\title{
Endoglin (CD105) is not a specific selection marker for endothelial cells in human islets of Langerhans. Reply to Wheeler-Jones CPD, Clarkin CE, Farrar CE et al [letter]
}

\author{
M. M. Zanone • E. Favaro • G. Camussi
}

Received: 1 October 2012 / Accepted: 3 October 2012 /Published online: 30 October 2012

(C) Springer-Verlag Berlin Heidelberg 2012

Keywords Islets of Langerhans · Endothelial cells ·

Mesenchymal stem cells $\cdot$ CD105

\author{
Abbreviations \\ MSC Mesenchymal stem cell \\ UEA-1 Ulex europaeus agglutinin-1 \\ VEGF Vascular endothelial growth factor
}

To the Editor: We agree with Dr Wheeler-Jones and colleagues that CD105 is not a specific marker for endothelial cells, being shared by other cell populations, including mesenchymal stem cells (MSCs) [1]. CD105 has been used to recover endothelial cells from several tissues, in combination with critical culture conditions, specifically endothelial basal medium (EBM) supplemented with specific endothelial growth factors $[2,3]$. This strategy generates, from isolated islets, cells expressing endothelial markers such as von Willebrand factor, CD31, vascular endothelial (VE)-cadherin, TNF- $\alpha$-upregulated E-selectin, induced HLA-DR molecules [4] and co-stimulatory molecules such as CD86 and inducible T-cell co-stimulator (ICOS) ligand [5], together with the expression of a panel of genes related to endothelial biology and the secretion of NO and vascular endothelial growth factor (VEGF)-A [3, 6]. This islet endothelium shows unique characteristics such as surface fenestrations and the presence of $\alpha-1$ proteinase inhibitor (also known as Api or $\alpha-1$ antitrypsin) and nephrin, a highly specific barrier protein [6]. In addition, the cells exhibit uptake of acetylated LDL and binding to Ulex europaeus agglutinin-1 (UEA-1) lectin. It is

M. M. Zanone $(\bowtie) \cdot$ E. Favaro $\cdot$ G. Camussi

Department of Internal Medicine, University of Turin,

Corso Dogliotti 14,

10126 Turin, Italy

e-mail: mmz@libero.it well established that viable endothelial cells persist within purified islets and, when freshly isolated and transplanted, contribute to neovascularisation [6].

On the other end, CD105 is one of the consensus markers for human MSCs, which lack an unambiguous single marker to clearly define these cells. Whether MSCs exist in vivo without tissue culture manipulation, or whether they are merely an in vitro phenomenon, is still matter of debate [7]. It has been postulated that, in the adult, tissue resident MSCs could be pericytes or vascular-associated cells of mesenchymal origin. Previous studies have isolated MSClike cells from human pancreatic islets [8]. Research data from our laboratory have shown that human islet-derived MSCs express CD105, CD73, CD90 and CD29 and do not express haematopoietic markers [9]. Moreover, these cells undergo efficient osteogenic and chondrogenic differentiation. In contrast to bone-marrow derived MSCs, adipogenic differentiation is observed only rarely [9]. In appropriate culture conditions, islet-derived MSCs have been shown to generate islet-like structures expressing C-peptide, and by proteomic analysis have been shown to exhibit a unique profile, compared with bone-marrow-derived, basal or differentiated MSCs [9]. These data indicate relevant differences in relation to cell origin, suggesting a partially committed state of islet-derived MSCs.

In line with their mesodermal origin, MSCs can differentiate in vitro into endothelial cells, following treatment with VEGF, and can contribute to vessel formation [10]. Therefore, the possibility cannot be excluded that endothelial cells obtained by CD105 sorting, followed by culture in medium containing VEGF, may also derive from endothelial differentiation of MSCs, or that both endothelial cells and MSCs derive from pericytes in different culture conditions [7].

Further investigations are needed to evaluate the cytoprotective effects of ghrelin gene products and exendin-4 on 
resident MSCs, in hyperglycaemic conditions. In fact, in the context of diabetes research, MSCs have been shown to be endowed with several possibilities that could be exploited. MSCs can generate insulin-producing cells, counteract autoimmunity, enhance islet engraftment, improve metabolic control in animal models for type 2 diabetes, and treat chronic diabetic complications [11]. Therefore, further studies on resident pancreatic islet MSCs, together with innovative strategies to induce less drastic cellular modifications, are welcomed.

Duality of interest The authors declare that there is no duality of interest associated with this manuscript.

Contribution statement MMZ, EF and GC were responsible for the conception, design, drafting and critical revision of the manuscript. All authors approved the final version to be published.

\section{References}

1. Wheeler-Jones CPD, Clarkin CE, Farrar CE et al (2012) Endoglin (CD105) is not a specific selection marker for endothelial cells in human islets of Langerhans. Diabetologia. doi:10.1007/s00125012-2763-2

2. Bussolati B, Deambrosis I, Russo S, Deregibus MC, Camussi G (2003) Altered angiogenesis and serviva in human tumor-derived endothelial cells. FASEB J 9:1159-1161
3. Favaro E, Granata R, Miceli I et al (2012) The ghrelin gene products and exendin- 4 promote survival of human pancreatic islet endothelial cells in hyperglycaemic conditions, through phosphoinositide 3-kinase/Akt, extracellular signal-related (ERK)1/2 and cAMP/protein kinase A (PKA) signalling pathways. Diabetologia 55:1058-1070

4. Favaro E, Bottelli A, Lozanoska-Ochser B, Ferioli E, Huang GC, Klein N et al (2005) Primary and immortalised human pancreatic islet endothelial cells: phenotypic and immunological characterisation. Diabetologia 48:2552-2562

5. Lozanoska-Ochser B, Klein NJ, Huang GC, Alvarez RA, Peakman M (2008) Expression of CD86 on human islet endothelial cells facilitates $\mathrm{T}$ cell adhesion and migration. J Immunol 9:6109-6116

6. Zanone MM, Favaro E, Camussi G (2008) From endothelial to beta cells: insights into pancreatic islet microendothelium. Curr Diabetes Rev 4:1-9

7. Alfaro MP, Young PP (2012) Lessons from genetically altered mesenchymal stem cells (MCSs): candidates for improved MSCderived myocardial repair. Cell Transplant 21:1065-1074

8. Davani B, Ikonomou L, Raaka BM, Geras-Raaka E, Morton RA, Marcus-Samuels B, Gershengorn MC (2007) Human islet-derived precursor cells are mesenchymal stromal cells that differentiate and mature to hormone-expressing cells in vivo. Stem Cells 25:32153222

9. Zanini C, Bruno S, Mandili G, Baci D, Cerutti F, Cenacchi G et al (2011) Differentiation of mesenchymal stem cells derived from pancreatic islets and bone marrow into islet-like cell phenotype. PLoS One 6:e28175

10. Galderisi U, Giordano A, Paggi MG (2010) The bad and the good of mesenchymal stem cells in cancer: Boosters of tumor growth and vehicles for targeted delivery of anticancer agents. World J Stem Cells 26:5-12

11. Pileggi A (2012) Mesenchymal stem cells for the treatment of diabetes. Diabetes 61:1355-1356 